\title{
Experimental and Computational Investigation of a MEMS-Based Boiler for Waste Heat Recovery
}

\author{
Suvhashis Thapa, Eric Borquist, Ashok Baniya, Leland Weiss ${ }^{\mathrm{a}}$ \\ ${ }^{a}$ Louisiana Tech University, College of Engineering and Science, P.O. Box 10348, \\ Ruston, LA 71272
}

\begin{abstract}
Thermodynamically limited processes make waste heat abundant in availability. An Organic Rankine Cycle (ORC) steam powered micro system designed to scavenge waste heat from various sources (transportation, industries or solar) is presented. The key boiler component is fabricated and characterized in this work. The system design has been inspired by the various efforts implemented in development of micro heat recovery devices and engines. The complete system consists of three individual micro components 1) boiler, 2) free piston expander and 3) superheater. Specifically, design, fabrication techniques, test setup and results of the miniaturized boiler are presented in this paper. A key design feature of the boiler is the inclusion of capillary channels for fluid flow from the surrounding reservoirs to the heated area. The pressurized steam is created by the boiler as a result of phase transformation of the working fluid. This pressurized steam can be utilized to drive another MEMS device (PZT membranes, turbines, thermoelectric, etc.) to
\end{abstract}

Email address: 1weiss@latech.edu (Leland Weiss)

$U R L:$ ww. latech.edu/ ${ }^{\sim}$ weiss (Leland Weiss)

Preprint submitted to Energy Conversion and Management

April 22, 2015

(C) 2015. This manuscript version is made available under the Elsevier user license http://www.elsevier.com/open-access/userlicense/1.0/ 
generate power. In this upgraded boiler design, radial capillary channels and a thin film glass steamdome were considered to improve the operating efficiency. These inclusions enhanced capillary flow, energy absorption via phase change, mass flow rate and operating pressure. The power inputs of $1.8 \mathrm{~W}$ and $2.7 \mathrm{~W}$ were selected to simulate and characterize the boiler performance based on real-world waste heat source temperatures. For these power inputs, the maximum power absorption efficiency demonstrated by the boiler via phase change of the working fluid was approximately $88 \%$. The peak operating pressure demonstrated by the boiler was $8.5 \mathrm{kPa}$. These thermally efficient characteristics of the boiler make it a potential future device for waste heat scavenging.

Keywords: Microboiler, Waste heat, Organic Rankine Cycle, Steam engine, Capillary channels

\section{Introduction}

In recent years, there has been increasing interest in development of 3 micro-devices and engines to recover waste heat. The reason is its free avail-

4 ability as well as abundance. Such availability is due to the inevitable losses 5 associated with thermodynamically limited processes. In a typical Otto cy6 cle for instance, out of the total energy consumed by the system, only one 7 third of the energy is converted into useful work and the rest is discharged 8 to the surrounding as a waste heat [1]. For a spark ignition 1.4 liter internal 9 combustion engine (ICE) with the thermal efficiency of $15 \%$ to $32 \%$, energy 
lost through the radiator is $1.7 \mathrm{~kW}$ to $45 \mathrm{~kW}$ and through exhaust gas is $4.6 \mathrm{~kW}$ to $120 \mathrm{~kW}[1,2]$. Likewise in industries, the estimated losses are in the range of $20 \%$ to $50 \%$ [3]. These losses could be minimized either by improving the efficiency of the system itself or via installation of secondary waste heat recovery system. The recovery system uses the losses to generate mechanical or electrical work to enhance the efficiency of the primary system [4]. Such notion of heat recovery is utilized in the microdevice presented in this paper.

The possibility of heat recovery using a microdevice was first validated by Muntz et al. in 1991 [5]. The study presented attractive characteristics of a pressure driven microdevice for power generation. Further, the author noted that the pressure driven microdevices required additional study. Since then several different microscale dynamic heat engine types have been investigated for waste heat recovery. Those are micro-sized gas turbines [6, 7] and rotary engines [8, 9], free piston engines [10, 11], and membrane type actuators for power generation [12]. The Brayton cycle based gas turbine was first proposed by Episein et. al.. Anticipated micro-device consisted of eight microscale components to fabricate the fully functional system. The power production by this device was calculated to be in the range of 10-100 $\mathrm{W}$ [7]. In recognition to this work, several other researchers initiated investigating of rotatory parts for power generation based on Rankine cycle steam engines $[8,13,14]$. The steam engines were further tailored to operate from low temperature waste heat sources by utilizing low boiling point refrigerants 
$[15,16,17]$. These micro-devices were called organic Rankine cycle (ORC) steam engines. The ORC based engines were comparatively less complex in design and more economical in terms of cost and maintenance [18]. A Wankel-type ORC engine with rotatory design was studied as well [19]. Apart from rotary engines, free piston Sterling engines were also investigated [20]. Metha et. al. presented a comparison of a sterling engine for waste heat recovery using two different ORC working fluids [21]. Similarly, performance of the low temperature solar powered differential sterling engine was also investigated. The study indicated a potentially attractive future low temperature engine [22]. In contrast to rotating and sliding engines, Washington State University introduced a P3 heat engine for power generation $[12,23]$. The engine was heated by an external heat source causing phase transformation of the working fluid to gas. The expansion of the fluid deflected the piezoelectric film attached to the silicon membrane producing power.Similar to this, Saturation Phase-change Internal Carnot Engine (SPICE) was studied as well [24]. With consideration of all these efforts in development of microdevices and engines for waste heat recovery, a system capable of scavenging waste heat is presented in this paper.

The system currently under investigation consists of three components: 1) boiler, 2) free piston expander (FPE), and 3) superheater. Figure 1 shows the ORC system in completion. The boiler is the particular emphasis of the work presented. The boiler consists of microfabricated capillary channels and steamdome. The capillary channel provides continuous supply of the 
fluid to the heated areas via capillary action, which would otherwise only be possible using a pump. The boilerplate captures the waste heat initiating phase change of the working fluid to vapor. The resulting steam traverses the superheater beneath the boiler. The pressurized superheated steam is then introduced to the FPE unit. The FPE constitutes the power output from the system and may produce either mechanical or electrical output depending on construction and need $[25,26,27]$. Following expansion in the FPE, the working fluid is cooled and returns to the boiler.

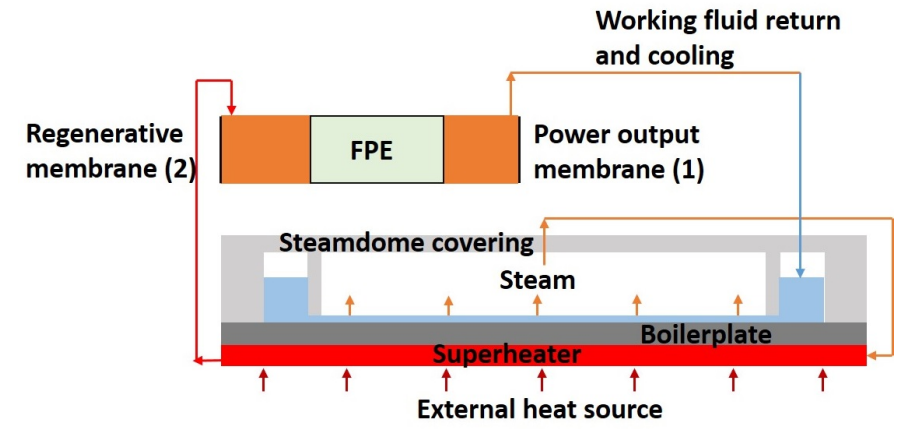

Figure 1: A waste heat scavenging system: the heat source, the steamdome covering, the boilerplate, the FPE and the superheater

${ }_{64}$ The work presented in this paper is focused on microscale boiler development area. The design and the microfabrication techniques utilized to manufacture the boiler are explained. The detail experimental plans and results obtained from the fabricated boiler are discussed in the flowing sections. 


\section{Experimental Materials and Method}

The microboiler tested and characterized in this work was based on the design of multiple capillary channels that accessed working fluid reservoirs. The channels transported fluid across the heated boilerplate surface where phase change was initiated. Once boiled, the working fluid was collected in a central steam dome with single outlet. In real-world operation, the outlet can be connected to other small-scale devices like a mechanical expander for final power output and delivery [25, 26, 27]. Figure 2 shows the basic operation and arrangement of the microboiler.

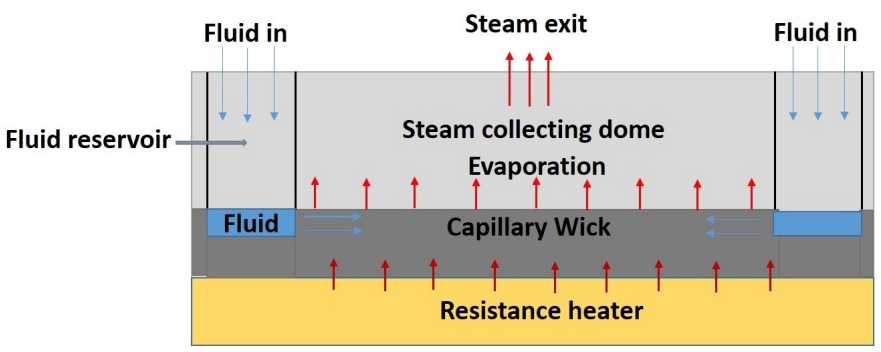

Figure 2: Working demonstration of the waste heat scavenging system

Capillary channels themselves were designed based on prior experimental work $[28,29,30]$ as well as expectations from open channel models [29, 31]. Two components were brought together to form the boiler. The boiler design consisted of (1) a boilerplate base with radially separated capillary channels and (2), a steam collecting dome. The overall dimension of the boiler was 35 $\mathrm{mm}$ by $35 \mathrm{~mm}$ by $1 \mathrm{~mm}$. Photolithographic masks were designed for each microboiler part to transform the design into the working prototype (see Figure 
3). A third and final mask was designed to etch inlet and outlet holes into the steamdome top. This avoided the need for any manual drill use. Each part was fabricated independently and then assembled. Additional components were then added to allow for full characterization of the completed boiler.

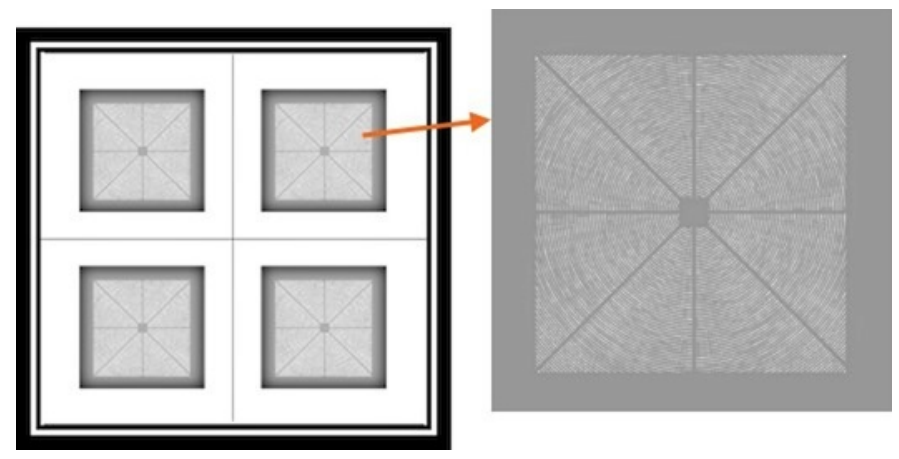

Figure 3: Boilerplate mask with an enlarged view of the boiler channel design

\subsection{Fabrication}

A 4 inch type $<100>$ silicon wafer was utilized to fabricate the base boilerplate. First, $200 \mathrm{~nm}$ thick aluminum was coated on one side of the wafer. This coating served as an etch stop in subsequent fabrication steps. The aluminum was then spin coated with S1813 photoresist (PR) and soft baked at $115^{\circ} \mathrm{C}$. The soft baked wafer was exposed and developed using MF319 developer for about 30 seconds. The developed wafer was then soaked in an aluminum etchant. The aluminum at the photolithographic exposed area was then stripped leaving silicon features beneath. ICP (Ion Couple Plasma) etching was performed on the silicon features to yield channels and the surrounding reservoirs. The depth and width of the capillary channels 
were $190 \mu \mathrm{m}$ and $100 \mu \mathrm{m}$ respectively. An image of one such fabricated boilerplate is shown in Figure 4.
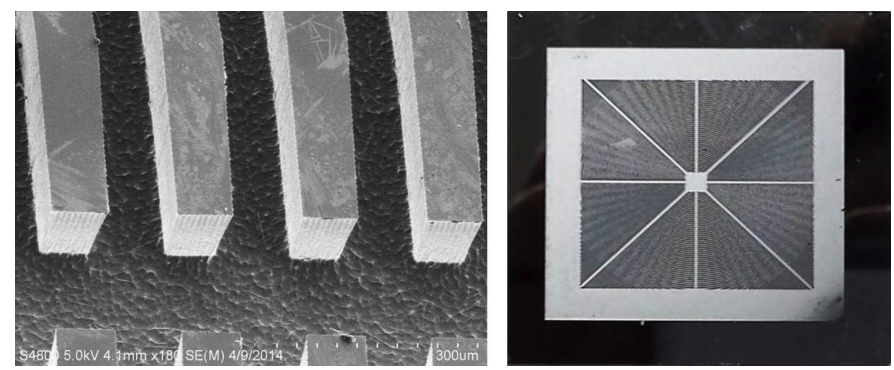

Figure 4: ICP etched boiler plate with a SEM image showcasing the enlarged channels

After the fabrication of the boilerplate, a glass wafer of similar dimension to the silicon wafer was selected for the steamdome fabrication. The glass was preferred as a material of fabrication because of its insulating properties. The glass also represented significant mass reduction as compared to prior work $[28,30]$. This reduced the steamdome thermal impact as part of boiler operation.

The glass wafer was coated with double layers of gold $\left(2000 A^{\circ}\right)$ atop a chrome layer $\left(200 A^{\circ}\right)$ on both sides of the wafer. This coating served as the etch stop for later processing steps, similar to the aluminum coating in boilerplate fabrication. The wafer was spin coated with S1813 PR on the both sides and soft baked for about 90 seconds at $115^{\circ} \mathrm{C}$. The soft baked wafer was exposed and developed to form the gold-chrome covered steamdome features on the front side of the glass wafer. The back side of the glass wafer was aligned to the front side using back side alignment (BSA) technique to form 
the inlet and the outlet holes. The aligned back side of the wafer was exposed and developed. The wafer was then soaked in gold and chrome etchant to remove the gold-chrome layer on the exposed surface. Finally, glass features that defined the specific shape and design of the steamdome were etched using an aqueous solution of hydrofluoric acid with an etch rate of $5 \frac{\mu m}{\mathrm{~min}}$. A diagram of the final steamdome design is shown in Figure 5.

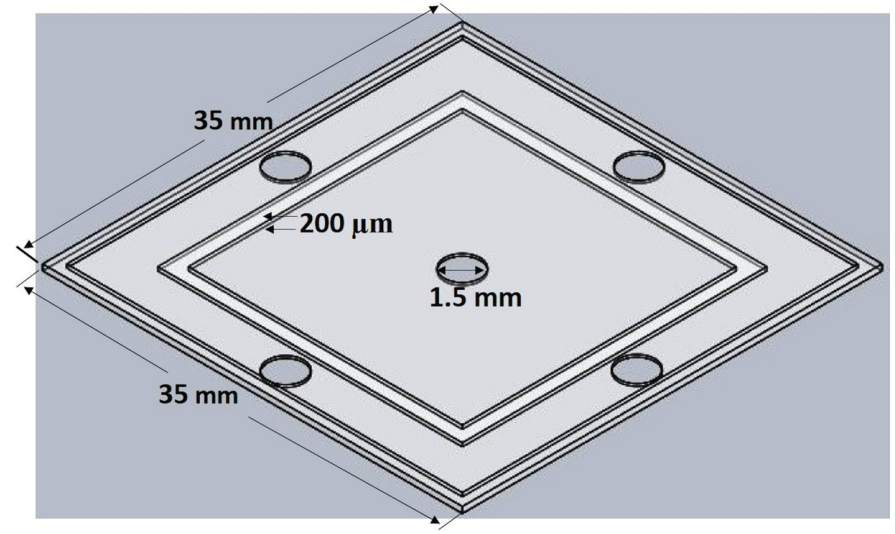

Figure 5: Diagram of fabricated glass steamdome

Each fabricated part was anodically bonded together to form the completed microboiler (see Figure 6). The bonding setup consisted of a hotplate and a pair of aluminum plates connected to a voltage supply. The individual parts were cleaned utilizing RCA-I and RCA-II techniques prior to the bonding process $[32,33]$. This removed any organic and inorganic contaminations attached to the bonding surface. The boilerplate and the glass steamdome were held in place using a pair of aluminum supports. The entire apparatus was then placed atop the hotplate. The hot plate was preheated to $400^{\circ} \mathrm{C}$ 
and a voltage of $400 \mathrm{~V}$ was supplied with the positive terminal connected to the silicon side [33]. The apparatus was visually inspected at 5 minute intervals to assess bonding progress. Relying on this verification, the voltage remained at $400 \mathrm{~V}$ or was increased up to $700 \mathrm{~V}$ to enhance bonding quality. After approximately 15-30 minutes, the anodically bonded boiler was obtained. Enclosed volumes for the working fluid and the steam collecting chamber were formed by bonding the boilerplate with the steamdome (see Figure 2). The boiler was now ready for the test setup and characterization.

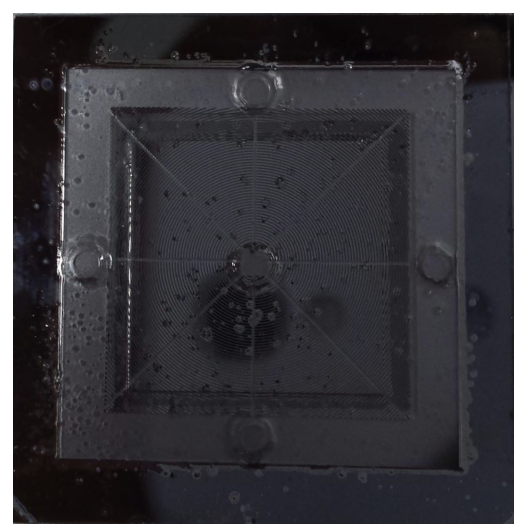

Figure 6: Top-down view of the anodically microboiler with steamdome and base

\subsection{Test Setup}

A number of different components were added to the completed boiler to allow for testing and characterization. These included fluid inlet and outlets, thermocouples (TC), pressure transducers, and heat flux sensors (HFS). For outlet from the boiler, a brass nipple fitting (supplied by McMaster-Carr) was attached to the central exit hole atop the steam collecting chamber. $\mathrm{T}$ 
shaped tubing was fitted to the brass nipple and then properly sealed using epoxy to avoid any leakage of vapor exiting the steamdome during operation. A pressure sensor type P600 (supplied by KAVLICO) was attached to the opening in line with the exit to monitor the microboiler operating pressure. Micro tubing (supplied by IDEX Health and Science LLC) approximately 8 $\mathrm{mm}$ long was fitted and sealed to the other opening end of the T-tube. This served as an outlet to the microboiler.

For the fluid inlet to the microboiler, micro tubing with a pressure sensor combined in-line was inserted into the inlet hole atop the reservoirs and epoxied in place to avoid fluid leakage during tests. The sensor monitored any back pressure exerted by the microboiler to the inlet flow. A resistance heater type KHLV-101/P (Omega Engineering Inc.) was used for the heat addition to the microboiler system. The heater was connected to a DC power supply (BK Precision). The supply was capable of reading both voltage and current in a heater connected circuit. This allowed determination of power supplied to the microboiler during testing. K-type thermocouples (Omega Engineering Inc.) were incorporated in the microboiler to monitor the temperature of the steam collecting chamber, the central part of the channels, the surrounding reservoirs and the outer surface of the steamdome. Additional thermocouples (TCs) were attached at the bottom of the microboiler to measure input or heater temperature. All attached sensors were connected to a data acquisition system (supplied by National Instruments) and then linked to a computer via LabVIEW SignalExpress software to automate recording. 


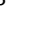

Figure 7 shows the microboiler with additional components included. Input powers of $1.8 \mathrm{~W}$ and $2.7 \mathrm{~W}$ were supplied to the heater for each series of tests. These powers were selected by comparing the resulting temperature of the heater with the waste heat temperature available from a typical 4 cylinder Otto cycle engine, a potential source for waste heat collection. Temperatures can range from approximately $600^{\circ} \mathrm{C}$ (exhaust) to $130^{\circ} \mathrm{C}$ (radiator) [34]. The temperatures reflected by the heater for the given power inputs were in this range and thus well suited for these investigations.

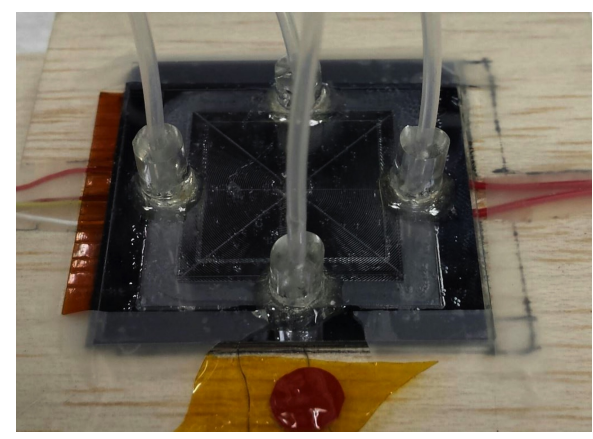

Figure 7: Microboiler test setup placed atop the balsa wood

174 Three independent experiments were performed on the microboiler to 175 fully understand the working capability of the boiler. The experiments were designated as: Dry, Atmospheric and Pressurized. Independent of test type, the boiler was first allowed to heat to steady state prior to data collection.

This was verified by monitoring of the operating temperature profiles of the boiler during warm-up. Figure 8 shows a typical temperature recording for a dry test. Steady state was achieved after approximately 12.5 minutes. 
A detailed explanation of all test setups and techniques are presented in the following sections. In addition, a detailed finite-difference model was generated to predict mass flow rate expectations of the boiler in operation.

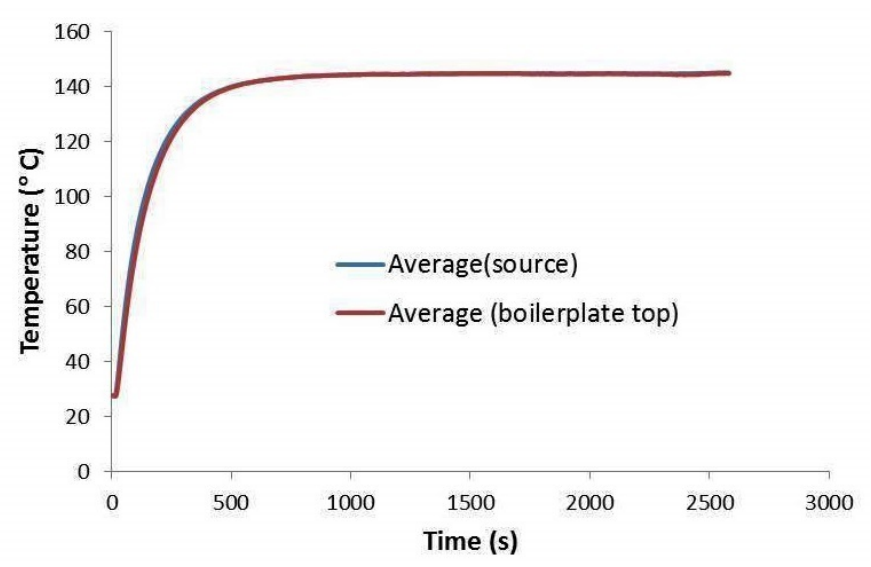

Figure 8: Typical operating temperatures in dry tests showing steady state

\subsubsection{Dry Test}

The Dry test was performed without supplying fluid to the boiler for each power input. The heat supply component consisted of a heat flux sensor (HFS) sandwiched between the two heaters. The heat supply component was then attached to the boiler (see Figure 9). Equal powers were supplied to the heaters and the HFS output was recorded. The HFS demonstrated a zero heat flux output. This indicated that there existed no temperature gradient between the top heater bottom surface and the bottom heater top surface allowing heat to flow in upward direction towards the boiler.

The experiment was conducted until a steady state temperature profile 
was achieved. The temperature data from the TCs were recorded. Temperature data allowed evaluation of temperatures at various locations of the microboiler for both levels of power input. Temperature readings were utilized for subsequent model validation work (Section 2.2.1) which was utilized to predict the available heat flux across the capillary channels for the phase change of fluid in the Wet tests (Atmospheric and Pressurized). Following completion of boiler operation without working fluid, the data was utilized in the modeling effort described in Section 2.2.2.

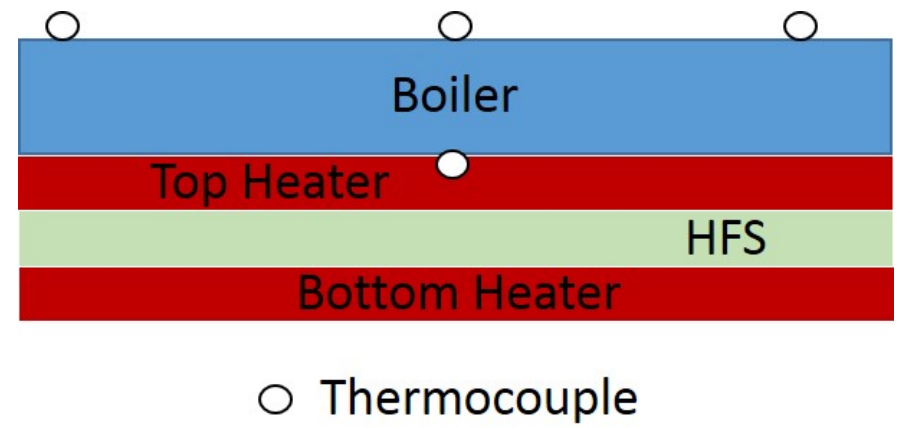

Figure 9: TCs attached at different locations of the microboiler setup

\subsubsection{Thermal Modeling}

A computational model using the Finite Difference Method (FDM) was generated that replicated the Dry test. The model allowed detailed evaluation of temperatures across the boiler plate and further utilized those temperatures to predict the energy available for phase change of the working fluid. This was utilized to establish expected working fluid consumption capability for the Wet tests. 


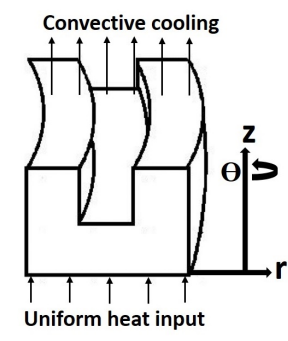

(a)

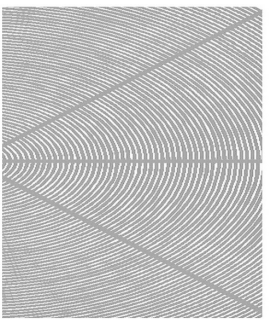

(b)

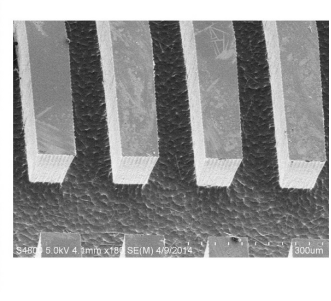

(c)

Figure 10: Model image of the axis (a), symmetry structures of the uniformly heated radial channels (b), and the enlarged view of the channels

A transient heat conduction model was employed assuming uniform temperature distribution across the capillary channels. This was due to the symmetry structure of the radial channels as shown in Figure 10. A single radial channel was considered and the temperature profile was assumed constant irrespective of change in the theta direction. This reduced the 3-D problem to a 2-D problem along the $r=x$ and $\mathrm{z}$ (thickness) directions. The model utilized FDM to discritize the heat exchanger into nodal points. The explicit transient heat conduction equation was solved at each nodal point to evaluate the temperature using Equation 1.

$$
\nabla^{2} T=\frac{\rho C_{p}}{k}\left(\frac{\partial T}{\partial t}\right)
$$

In Equation 2, T, t, $\rho, C_{p}$ and $\mathrm{k}$ are the temperature, time, density, specific heat capacity and conductivity, respectively. The material property of silicon and the dimensions of the wall and the channel were considered. The convection condition at appropriate nodes was also included in the model. 
The convection coefficient of approximately $18 \frac{W}{m^{2} K}$ was considered in the model. This was determined by introducing known values of supplied heat flux (q), the resulting temperature via conduction (T) and the ambient temperature $\left(T_{\text {infinity }}\right)$ as recorded in the initial Dry test operation. Equation 2 shows the subsequent calculation of $\mathrm{h}$, the convection coefficient. Moreover, the calculated value of $\mathrm{h}$ was also well in line with the natural convection range of approximately 5 to $20 \frac{W}{m^{2} K}[13],[14]$.

$$
h=\frac{q}{\left(T-T_{\text {infinity }}\right)}
$$

Figure 11 shows the 2-D geometry utilized for the model. Appropriate initial and boundary conditions were applied to replicate the real-world Dry test. The temperature profile across the model was obtained by converging iteration based on energy difference $\left(E_{\text {in }}-E_{\text {out }}\right)$. It was maintained as low as micro-Watts for each power input. The nodal temperature generated via modeling was compared with the Dry test temperature result to validate the model. After this validation, the amount of thermal energy available from the channels to deliver to the fluid was evaluated. The heat flux generated by the model was utilized to calculate the mass feed rate into the boiler. It is essential to determine the fluid feed rate prior to the Wet tests (Atmospheric and Pressurized). The mathematical calculation for the maximum mass feed rate $(\dot{m})$ is given by Equation 3. In Equation 3, the available heat flux $\left(P_{\text {available }}\right)$ is divided by the working fluid heat of vaporization to yield the 
mass feed rate. $\left(P_{\text {available }}\right)$ was provided by the model the heat of vaporization $\left(\Delta H_{v}\right)$ was acquired from known properties of the working fluid used in all Wet tests.

$$
\dot{m}=\frac{P_{\text {available }}}{\Delta H_{v}}
$$

245 In this work, 3MNOVEC ${ }^{T M} H F E-7200$ was selected as the working fluid. This was dependent on several things including the temperature at the boilerplate and other fluid properties like fluid-surface contact angle that enhanced capillary action, high heat of vaporization, and low environmental impact. This fluid has a favorable low boiling temperature of $76^{\circ} \mathrm{C}$ which was appropriate for the study. It also demonstrated high wettability with the surface. In addition, it presented high heat of vaporization $\left(\Delta H_{v}\right)$ of about $125 \frac{\mathrm{kJ}}{\mathrm{kg}}$ and low environmental impact [29]. Due to these favorable fluid properties, refrigerants has been utilized for boiling heat transfer in several studies $[35,36]$. Considering HFE-7200 as the working fluid the mass flow rate was determined. This readied boiler for the Wet tests.

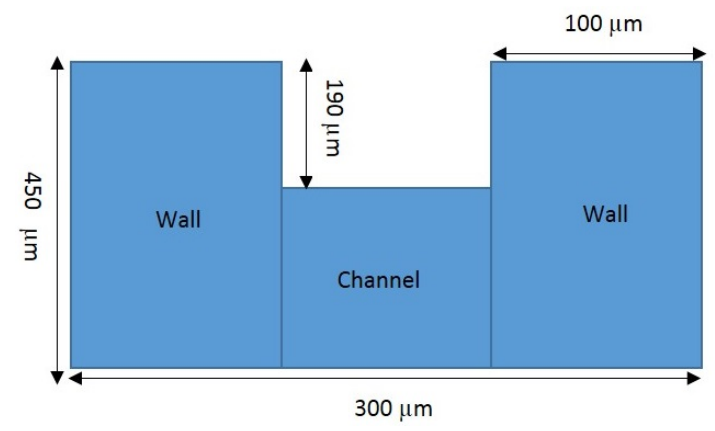

Figure 11: A 2-D profile of the 3-D symmetry capillary channel 


\subsubsection{Atmospheric Test}

In the Atmospheric test, the boiler was operated at atmospheric pressure with working fluid supplied. The working fluid mass exiting the microboiler due to phase change of the supplied working fluid was studied for each individual power input. The atmospheric test provided insight into the potential of the capillary channels to pump fluid at ambient condition and allowed the determination of a boiler efficiency parameter (energy absorbed via phase change of the fluid $\left.\left(P_{e v a}\right)\right)$ as defined by Equation 4 .

$$
\operatorname{Efficinecy}(\%)=\frac{P_{\text {eva }}}{P_{\text {available }}} \times 100 \%
$$

Figure 12 shows the test setup with a clamp included that was used to obstruct the exit of the boiler. The clamp was important to subsequent pressurized testing but was not utilized in these atmospheric tests. In these tests, boiler operating pressure was maintained at atmospheric conditions, hence the outlet was left open. A constant heat was supplied from the heater attached to the bottom of the boiler. The temperature and the pressure data were monitored. The boiler was heated for about 12.5 minutes to attain steady state (see Figure 8). After steady state was achieved, the predicted flow rate in the Section 2.1.2 via modeling was supplied.

The working fluid was supplied to the boiler via inlet tubing connected to a syringe/infusion pump. The infusion pump was utilized in order to accurately monitor mass flow rates supplied to the boiler. Phase change 


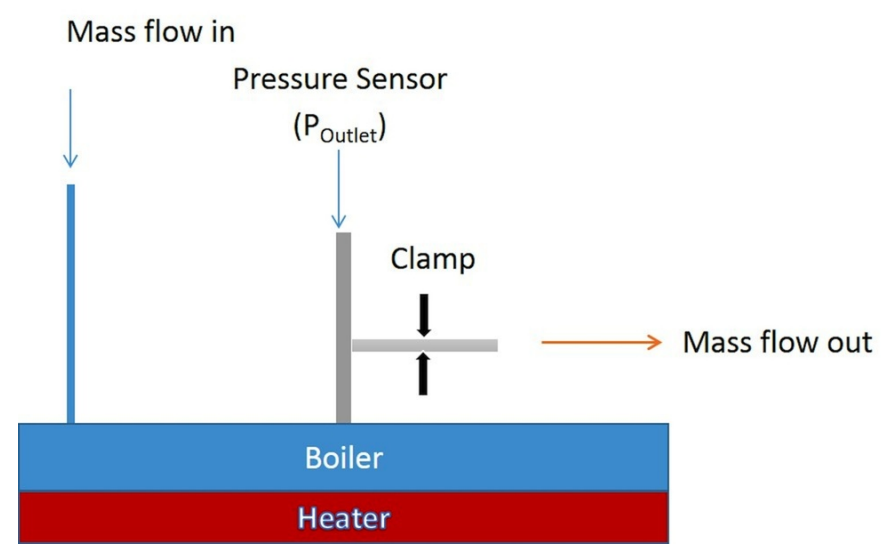

Figure 12: Atmospheric and Pressurized test setup

occurred on the heated boiler plate as working fluid entered and heated within the capillary channels. Working fluid exiting the boiler was collected in a 10cc plastic syringe and cooled using ice cubes surrounding the syringe for the fixed period of about 4 minutes. Cooling the working fluid in ice cubes ensured full condensation of the collected boiler outflow. The mass of the collected fluid was measured via precision scale. The measured mass was then divided by duration of the test and the energy absorbed due to phase transformation of the fluid. In this way, the efficiency of the boiler for each power input was determined.

\subsubsection{Pressurized Test}

Following the Atmospheric test, the pressurized test was performed on the boiler. In this test, the boiler was operated at elevated pressure. This allowed investigation of capillary channel ability to effectively pump fluid at different operating pressures. 
The test setup was similar to the setup presented in Figure 12, however, this time making use of the clamp. The clamp provided obstruction to boiler exit, allowing operation under a pressurized environment. Pressurized testing commenced in similar fashion to atmospheric testing. First, the boiler was heated to steady state at the given power input $(1.8 \mathrm{~W}$ or $2.7 \mathrm{~W})$. The temperature and pressure data were recorded. Working fluid was introduced based on the modeling effort described in Section 2.2.2 with initial supply matching atmospheric test conditions. The boiler was then pressurized via clamp application and the flow rate supplied to the boiler was reduced to match the reduced mass flow leaving the boiler. This prevented an oversupply condition to the boiler operation.

This technique was verified by visualizing the temperature and the pressure profile of the boiler over the duration of operation. In these pressurized tests, the test duration was 2 minutes. For each degree of restriction and its adjusted flow rate, the temperature and the pressure data were recorded. These tests provided the insight into saturation temperature and corresponding pressure for the specific flow rate. However, to formally verify the operating condition of the boiler during elevated pressure testing, additional components and analysis were employed.

\subsubsection{Superheater Test}

Superheater components and tests were employed to fully validate and characterize boiler operation. The use of the superheater was used in these 
tests to fully validate boiler operation and working fluid thermodynamic state. The superheater successfully elevated the temperature of the working fluid beyond saturation conditions to full superheat as validated by $3 M^{T M}$ thermodynamic tables. By monitoring pressure and temperature of the working fluid leaving the boiler and traversing the superheater, additional test points allowed characterization of boiler operation through the saturation conditions of the working fluid and along lines of constant pressure superheat. In real-world applications, a superheater may be employed to increase energy available to connected power output devices.

Using the basic boiler test setup (Section 2.2), additional components for superheat of the working fluid were added that included pressure sensor, TCs, and two resistance heaters. First, the outlet from the boiler was connected directly to the in-house built superheater. Figure 13 shows the additional components employed along with arrows pointing data collecting locations.

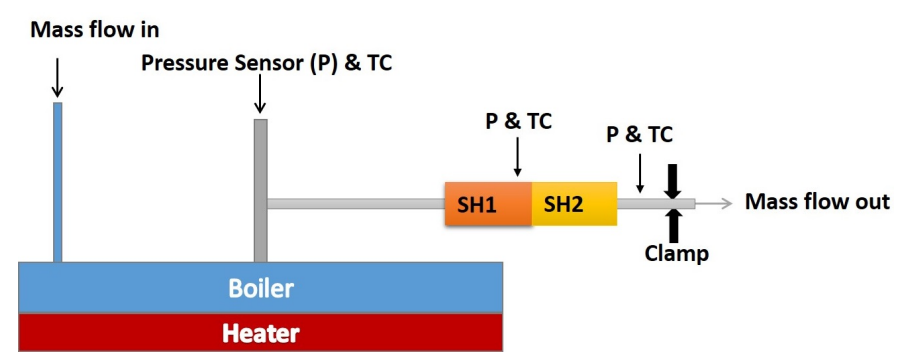

Figure 13: Super heater test setup with all included components

326 In fabrication of the superheater, two micro-sized copper tubes of equal length were utilized. Each tube was carefully bent in serpentine manner to 
allow maximum exposure to additional resistance heaters that were attached around the bends (see Figure 14(a)). This presented two distinct sections of the superheater where temperature and pressure data could be monitored between sections. The heaters were then connected to separate voltage supplies with the capability of voltage and current read outs. T-tubing connected the two sections of serpentine superheater tubes and allowed an inline pressure sensor and TC to monitor working fluid conditions. A second T-tubing was connected to the outlet of the second superheater with a second pressure sensor and TC. Finally, boiler output was attached directly to one end of the combined superheater sections. Figure 14(b) shows the device with heaters and tubing enclosed below insulation marked SH1 (Superheat 1) and SH2 (Superheat 2). All the connections were checked and then sealed properly to avoid any leakage of vapor during testing.

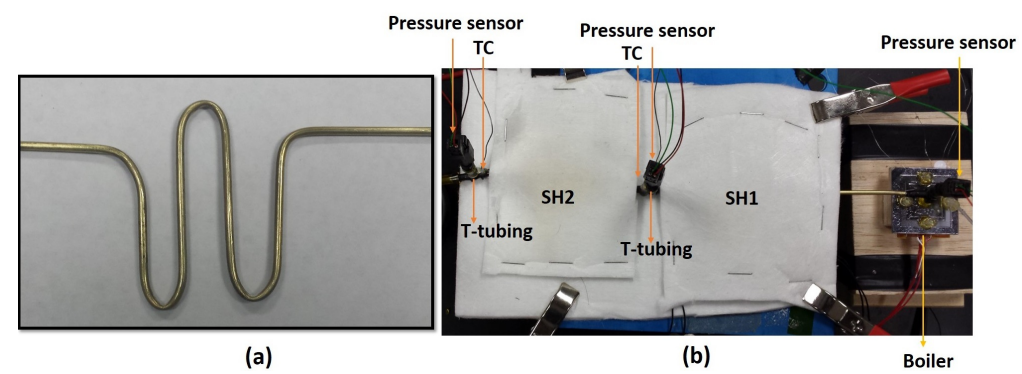

Figure 14: (a) Copper tube bent in serpentine manner, (b) Boiler test setup with connected superheater

Operation of the boiler and superheater commenced with the full setup heating to steady state. All temperature and the pressure data was recorded. Table 1 shows the full list of pressure recordings (by location) and tempera- 
355

ture readings (by location). As before, working fluid flow rates were utilized based on atmospheric testing of the boiler, then reduced as operating pressure increased for each test. Several tests were conducted to investigate operating pressure versus saturated temperature and superheated temperature correlations. In this approach, first the vapor temperature was maintained constant in the entire setup (boiler and superheater). This allowed the operation at saturated region of the fluid. To operate at the superheated region, the power to the superheater was increased in steps to further raise the temperature of the incoming vapor from the boiler. For each test, resulting vapor temperature and pressure were noted. The test was then repeated for a different flow rate and operating pressure. The noted pressure data was then utilized to verify boiler operation along the isobars of the working fluid.

Table 1: List of pressure $(\mathrm{P})$ recording and temperature $(\mathrm{T})$ recording by locations

\begin{tabular}{|c|c|c|}
\hline Boiler $(P, T)$ & $S H 1(P, T)$ & $S^{2} 2(P, T)$ \\
\hline $\begin{array}{l}\text { Vapor temperature and } \\
\text { pressure monitored inside } \\
\text { the steam collecting dome } \\
\text { or at the boiler exit }\end{array}$ & $\begin{array}{l}\text { Temperature and pressure } \\
\text { recorded at the outlet of } \\
\text { SH1 or between the } \\
\text { superheaters (SH1 and } \mathrm{SH} 2 \text { ) }\end{array}$ & $\begin{array}{c}\text { Temperature and pressure } \\
\text { of the steam recorded } \\
\text { at the exit of the } \\
\text { setup }\end{array}$ \\
\hline
\end{tabular}

\subsection{Experimental Error}

Kline and McClintock uncertainty analysis was utilized to evaluate the error associated with the test data [37]. The error associated with the voltage and the current readings were $\pm 0.1 \mathrm{~V}$ and $\pm 0.001 \mathrm{amp}$, respectively. The error associated with each power input was $\pm 9 \mathrm{mV}$. Error associated with temperature, mass of the fluid and time were on the order of $\pm 0.5^{\circ} \mathrm{C}, \pm 0.005 \mathrm{~g}$ and 
\pm 1 second, respectively. The error associated with each individual evaporation rate was determined to be in the order of $\pm 0.56 \frac{\mathrm{mg}}{\mathrm{s}}$. The error associated with the pressure reading was $\pm 0.5 k P a$.

\section{Result and Discussions}

The microboiler consisted of a boilerplate base and a steamdome covering top. These parts were fabricated separately and then anodically bonded to form the boiler. The fabricated boiler was then equipped with additional components to fully ready it for testing. The tests were categorized as the Dry test and the Wet test (Atmospheric and Pressurized). In the Dry test, the operational characteristics were tested without supplying any working fluid to the boiler. These included selection of the power inputs and monitoring of the temperatures for the supplied power inputs at different locations of the boilerplate. Using these temperatures, the computational model was validated. The validated model was then utilized to discern heat available at the channel for the evaporation of the working fluid. This generated heat flux was further utilized to evaluate working fluid mass flow rate. These combined results established the working baseline for the Wet test.

In the Wet Test, two sets of tests were performed on the microboiler utilizing the established baseline from the Dry test. First was the atmospheric test in which the boiler was operated in the atmospheric pressure. In this test, the boiler ability to pump fluid out of the boiler via phase change was evaluated. This provided one measure of boiler efficiency. Second, the boiler 
was operated in a pressurized condition to investigate the working capability of the capillary channels to draw fluid under the pressurized environment. This test was then extended by including superheaters at the outlet of the boiler. Results from this test were utilized to validate boiler operation along the isobaric pressure line of the working fluid. Reporting of these test results is presented in the following sections.

\subsection{Dry Test}

A resistance heater and the K-type thermocouples (TC) were utilized to supply heat at the bottom of the boilerplate and to measure temperatures at different locations of the microboiler, respectively. The power supplied to the heater were selected to replicate real-world available heat sources as noted in Section 2.2. Power inputs of $1.8 \mathrm{~W}$ and $2.7 \mathrm{~W}$ were selected which yielded the heater temperatures of about $106^{\circ} \mathrm{C}$ and $144^{\circ} \mathrm{C}$, respectively.

Power was supplied and the temperatures were recorded at locations indicated in Figure 8. After steady state was achieved, the test was run for approximately 15 minutes and the temperature readings were averaged (see Figure 7). Table 2 shows the recorded temperatures. The average temperature at the boilerplate top were $105.5^{\circ} \mathrm{C}$ and $143^{\circ} \mathrm{C}$ for the power inputs of $1.8 \mathrm{~W}$ and $2.7 \mathrm{~W}$, respectively.

\subsection{Thermal Modelling}

The Dry experimental test provided the power inputs $\left(P_{i n}\right)$ and corresponding temperatures of the heater and the temperature at the top of the 
Table 2: Temperature reading of the boilerplate

\begin{tabular}{|c|c|c|}
\hline $\begin{array}{c}P_{\text {in }} \\
(\mathrm{W})\end{array}$ & $\begin{array}{c}\text { Reservior } \\
\left({ }^{\circ} \mathrm{C}\right)\end{array}$ & $\begin{array}{c}\text { Center of Channel } \\
\left({ }^{\circ} \mathrm{C}\right)\end{array}$ \\
\hline \hline 1.8 & 142 & 144 \\
2.7 & 105 & 106 \\
\hline
\end{tabular}

boilerplate. This data was utilized in the model as described in Section 2.2.2.

The designed model replicated real test conditions to accurately provide the heat flux available at the channel for the phase conversion of the fluid. The temperature distributions of the simulated model with $1.8 \mathrm{~W}$ power input is presented in Figure 15.

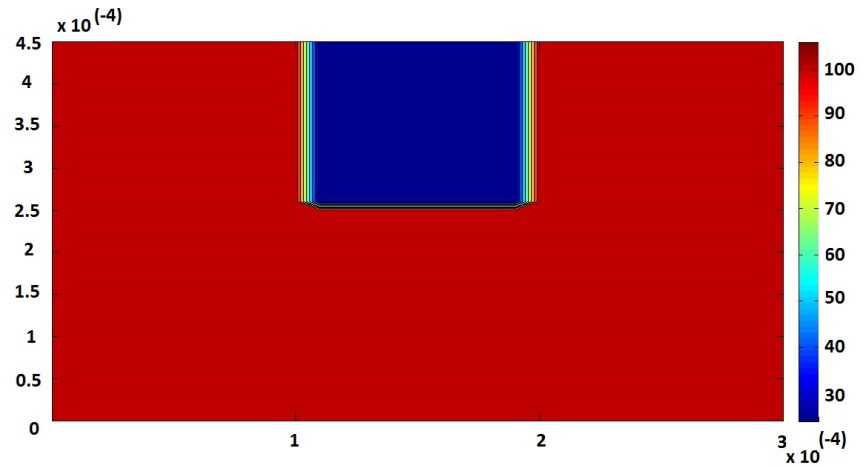

Figure 15: Temperature distribution with $1.8 \mathrm{~W}$ power supply

In order to verify the simulation, results obtained were compared to the Dry test temperatures. The comparison of the results are summarized in Table 3. The maximum discrepancy in the test and simulation model result was less than $\pm 5 \%$. This validated the accuracy of the model.

The heat fluxes indicated by the model as available for phase change of the fluid were $1.14 \mathrm{~W}$ and $1.72 \mathrm{~W}$ for $1.8 \mathrm{~W}$ and $2.7 \mathrm{~W}$, respectively. These 
Table 3: Comparison of the Dry test and the model

\begin{tabular}{|c|c|c|c|c|}
\hline \multicolumn{2}{|c|}{$\begin{array}{c}\text { Input Power }\left(P_{\text {in }}\right) \\
(\mathrm{W})\end{array}$} & \multicolumn{2}{|c|}{$\begin{array}{c}\text { Average Temperature } \\
\left({ }^{\circ} \mathrm{C}\right)\end{array}$} & $\begin{array}{c}\text { Available Heat flux } \\
(\mathrm{W})\end{array}$ \\
\hline \hline 1.8 & 1.8 & 105.5 & 105.9 & 1.14 \\
2.7 & 2.7 & 143 & 143.9 & 1.72 \\
\hline
\end{tabular}

417

determined heat fluxes were then utilized to establish expected working fluid mass flow feed rates into the boiler for the Wet Test (Section 2.2.2.) The mass flow rate for each power input is presented in Table 4. The mass flow rates were $9 \frac{\mathrm{mg}}{\mathrm{s}}$ and $13.6 \frac{\mathrm{mg}}{\mathrm{s}}$ for the power inputs of $1.8 \mathrm{~W}$ and $2.7 \mathrm{~W}$, respectively.

Table 4: Determination of the mass flow rate

\begin{tabular}{|c|c|c|c|}
\hline $\begin{array}{c}P_{\text {in }} \\
(\mathrm{W})\end{array}$ & $\begin{array}{c}P_{\text {available }} \\
(\mathrm{W})\end{array}$ & $\begin{array}{c}\Delta H_{v} \\
\left(\frac{\mathrm{kJ}}{\mathrm{kg}}\right)\end{array}$ & $\begin{array}{c}\dot{m} \\
\left(\frac{m g}{\mathrm{~s}}\right)\end{array}$ \\
\hline \hline 1.8 & 1.14 & 125 & 9.12 \\
2.7 & 1.72 & 125 & 13.6 \\
\hline
\end{tabular}

\subsection{Atmospheric Test}

Following approximation of the mass flow rates, the boiler was ready for tests involving fluid with power input and fluid supply rates shown in Table 4. The typical temperature profile of the boiler before and after the fluid supply is illustrated in Figure 16 for power input of $1.8 \mathrm{~W}$.

Vaporized fluid exiting out of the boiler was collected and weighed as described in Section 2.2.3. A set of three tests was performed for each power input. Results were averaged and are presented in Table 5.

The calculated averaged mass flow rate in Table 3 was combined with the heat of vaporization of HFE-7200 to determine energy absorbed via phase 


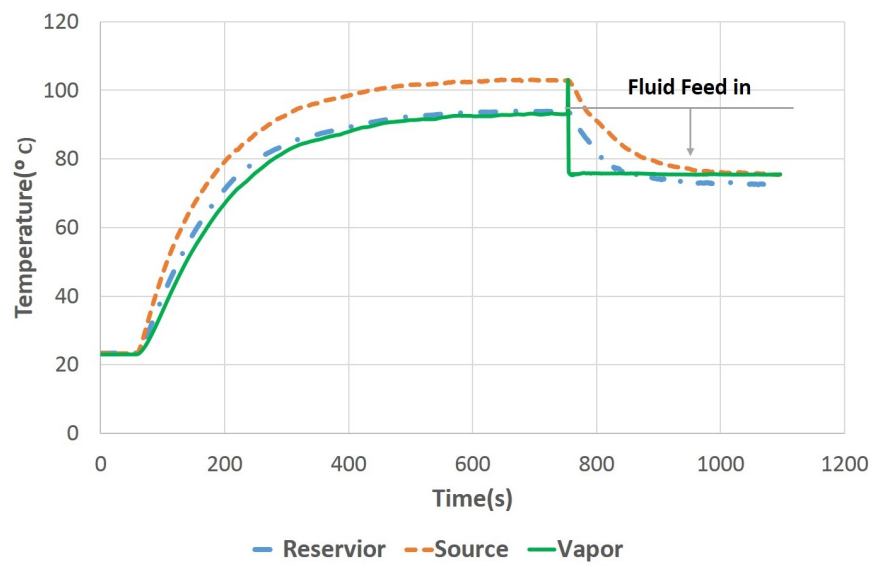

Figure 16: Temperature profile of the heat source, the reservoir and the steam

Table 5: Measured temperature and the mass flow rate for each power input

\begin{tabular}{|c|c|c|c|c|c|c|}
\hline $\begin{array}{c}P_{\text {in }} \\
(\mathrm{W})\end{array}$ & \begin{tabular}{c}
$P_{\text {available }}(\mathrm{W})$ \\
\hline \hline
\end{tabular} & $\begin{array}{c}\text { Source } \\
\text { Temperature } \\
\left({ }^{\circ} \mathrm{C}\right)\end{array}$ & $\begin{array}{c}\text { Steamdome } \\
\text { Temperature } \\
\left({ }^{\circ} \mathrm{C}\right)\end{array}$ & $\begin{array}{c}\text { Vapor } \\
\left({ }^{\circ} \mathrm{C}\right)\end{array}$ & $\begin{array}{c}\text { Mass Feed } \\
\text { Rate } \\
\left(\frac{m g}{s}\right)\end{array}$ & $\begin{array}{c}\text { Average Mass } \\
\text { Exit Rate } \\
\left(\frac{m g}{s}\right)\end{array}$ \\
\hline \multirow{2}{*}{1.8} & 106 & 75.1 & 75.6 & 9 & 8 \\
& \multirow{2}{*}{1.14} & 106 & 75.1 & 75.6 & 9 & 8 \\
& \multirow{2}{*}{1.72} & 106 & 75.1 & 75.6 & 9 & \\
& 144 & 75.1 & 75.6 & 13.6 & \multirow{2}{*}{11.9} \\
\hline
\end{tabular}

change of the working fluid and the efficiency of the microboiler. Figure 17 illustrates the comparison of the power input and the power observed via phase transformation of the fluid supplied.

The boiler demonstrated the phase conversion rates of $8 \frac{\mathrm{mg}}{\mathrm{s}}$ and $11.9 \frac{\mathrm{mg}}{\mathrm{s}}$ for the fluid inputs of $9 \frac{\mathrm{mg}}{\mathrm{s}}$ and $13.6 \frac{\mathrm{mg}}{\mathrm{s}}$, respectively. These values showed improvement versus boilers presented in prior efforts where a larger dimension acrylic steamdome was utilized $[28,30]$. The use of a thin glass wafer 


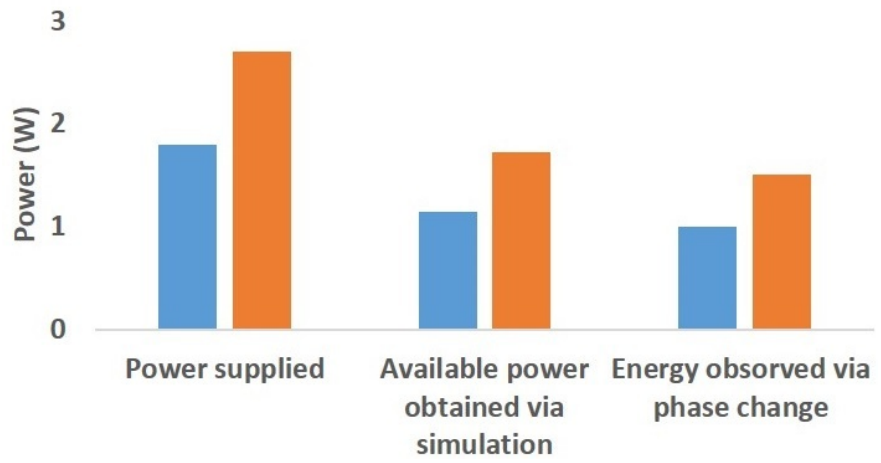

Figure 17: Supplied power vs power observed via phase change

Table 6: Efficiency of the microboiler

\begin{tabular}{|c|c|c|c|}
\hline $\begin{array}{c}P_{\text {available }}(\mathrm{W}) \\
\left(\frac{\mathrm{kJ}}{\mathrm{kg}}\right)\end{array}$ & $\begin{array}{c}P_{\text {evaporation }} \\
\left(\frac{\mathrm{mg}}{\mathrm{s}}\right)\end{array}$ & $\begin{array}{c}\text { Efficiency }(\eta) \\
(\%)\end{array}$ \\
\hline \hline 1.14 & 125 & 1 & 87.8 \\
1.72 & 125 & 1.48 & 86.2 \\
\hline
\end{tabular}

as a steamdome eliminated a significant heat sink effect previously encountered. It should be noted that the temperature of the steamdome and vapor are almost equal. This allowed vapor to exit the boiler without premature condensation, thus improving the boiler operation.

Despite improved operation, some loss of working fluid mass was encountered. The boiler presented a maximum mass loss of about $12 \%$. This loss was likely the result of the volatile nature of the HFE-7200 fluid combined with the capture and mass measure technique. To verify this assertion, an additional test was performed that replaced HFE-7200 fluid with water. This eliminated the volatile behavior of the HFE-7200 and verified the accuracy of the mass measurement. 
As with HFE 7200 as the working fluid, the boiler was heated to steady state and water was supplied. The phased changed vapor was collected and condensed. The comparison of the measured mass flow rate out of the boiler at $1.8 \mathrm{~W}$ power input using water and HFE-7200 as the working fluid is summarized in Table 7. For comparison, results obtained using water demonstrated significantly reduced loss. Approximately $98 \%$ of the water supplied was collected following exit from the boiler. This is not an unexpected result as indicated by formal HFE properties supplied by $3 M^{T M}$. The typical evaporative losses for the HFE-7200 is approximately in the range of $339 \frac{m g}{\left(s-m^{2}\right)}$ to $1017 \frac{m g}{\left(s-m^{2}\right)}$ when exposed to ambient temperature and pressure [38].

Table 7: Comparison of the mass flow rate for the different fluids

\begin{tabular}{|c|c|c|c|}
\hline $\begin{array}{c}\text { Workig Fluid } \\
\text { Type }\end{array}$ & $\begin{array}{c}P_{\text {in }} \\
(\mathrm{W})\end{array}$ & $\begin{array}{c}\text { Mass Feed Rate } \\
\left(\frac{\mathrm{mg}}{\mathrm{s}}\right)\end{array}$ & $\begin{array}{c}\text { Mass Exit Rate } \\
\left(\frac{\mathrm{mg}}{\mathrm{s}}\right)\end{array}$ \\
\hline \hline & & 6 & 5.9 \\
Water & 1.8 & 6 & \\
& & 6 & 8 \\
\hline & & 9 & \\
HFE-7200 & 1.8 & 9 & \\
& & 9 & \\
\hline
\end{tabular}

\subsection{Pressurized Test}

The mass flow rate and power input were supplied to the boiler as shown in Table 4. The boiler was allowed to operate at atmospheric pressure and then the outlet tubing was restricted. The flow rate supplied to the microboiler was then adjusted to match the mass flowing in and leaving out of the boiler as explained in Section 2.2.4. Figure 18 shows the temperature and pressure profile for each adjusted flow rate to the boiler with $1.8 \mathrm{~W}$ input. 


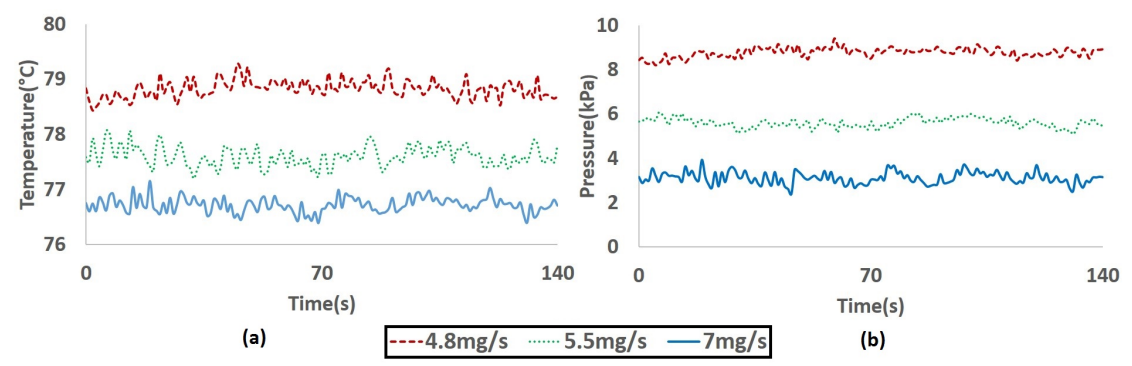

Figure 18: Temperature (a) and pressure (b) trends by varying restriction to the boiler exit for $1.8 \mathrm{~W}$ power input

Similarly, Figure 19 shows the temperature and the pressure profile for each adjusted flow rate to the boiler for the $2.7 \mathrm{~W}$ power input.

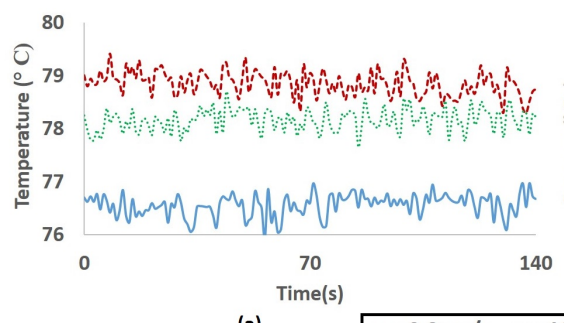

(a)

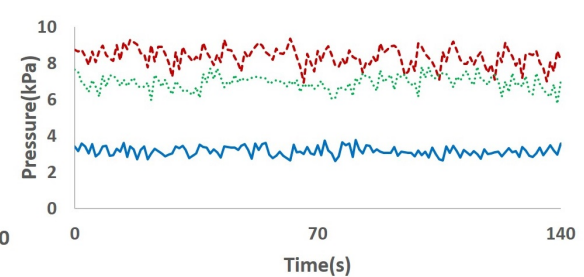

(b)

Figure 19: Temperature (a) and pressure (b) trends by varying restriction to the boiler exit for $2.7 \mathrm{~W}$ power input.

The data in Figure 18 and Figure 19 were averaged and the standard deviation associated with each temperature and pressure calculation are summarized in Table 8 for all power inputs.

Based on Table 8, pressure versus temperature data were plotted as a function of the mass flow rate for each power input (see Figure 20). The boiler operating temperature and pressure were increased as restriction on the boiler exit was increased. In good agreement with a saturated working 
Table 8: The average temperature and pressure for each flow rate along with supplied power

\begin{tabular}{|c|c|c|c|}
\hline $\begin{array}{c}P_{i n} \\
(\mathrm{~W})\end{array}$ & $\begin{array}{c}\text { Mass feed rate } \\
\left(\frac{m g}{s}\right)\end{array}$ & $\begin{array}{c}\text { Vapor Temperature } \\
\left({ }^{\circ} \mathrm{C}\right)\end{array}$ & $\begin{array}{c}\text { Pressure } \\
(\mathrm{kPa})\end{array}$ \\
\hline \hline & 9 & 75.6 & $0 \mathrm{~g}$ \\
& 7 & $76.7 \pm 0.14$ & $3 \pm 0.3$ \\
1.8 & 5.5 & $77.6 \pm 0.2$ & $5.6 \pm 0.2$ \\
& 4.8 & $78.8 \pm 0.2$ & $8.8 \pm 0.2$ \\
\hline & 13.6 & 75.6 & $0 \mathrm{~g}$ \\
& 11.4 & $76.6 \pm 0.3$ & $3 \pm 0.4$ \\
2.7 & 10 & $78 \pm 0.3$ & $6.9 \pm 0.4$ \\
& 9.3 & $78.9 \pm 0.35$ & $8.5 \pm 0.2$ \\
\hline
\end{tabular}

condition, pressure and temperature data demonstrated that vapor temperature followed the increasing trend of operating pressure inside the steamdome. This was true for all power inputs as well as when theses power inputs were compared to each other for particular pressure point. For the operating pressure of $3 \mathrm{kPa}$, the saturated temperature of the steam was approximately $76.7^{\circ} \mathrm{C}$ for both the power inputs. Such phenomenon were visualized for other operating pressures as well (see Figure 20). This validates for the specific saturated pressure there exists a unique saturated temperature and the boiler operation as saturated. Moreover, the pressurized test provided the saturated temperature and pressure points of the HFE-7200 working fluid.

To obtain the superheated properties of the HFE-7200 working fluid, the temperature of the steam exiting the boiler was further raised. The results from the test are presented in the following section. 
Table 9: The temperature and the pressure recording of the vapor by location

\begin{tabular}{|c|c|c|c|c|c|c|c|}
\hline \multirow[t]{3}{*}{$\begin{array}{l}P_{\text {in }} \\
(\mathrm{W})\end{array}$} & \multirow[t]{3}{*}{$\begin{array}{l}\text { Feed Rate } \\
\qquad\left(\frac{m g}{s}\right)\end{array}$} & \multicolumn{3}{|c|}{$\begin{array}{l}\text { Vapor Temperature } \\
\left({ }^{\circ} \mathrm{C}\right)\end{array}$} & \multicolumn{3}{|c|}{$\begin{array}{c}\text { Operating Pressure }(\mathrm{kPa}) \\
\qquad(\mathrm{kPa})\end{array}$} \\
\hline & & Boiler & SH1 & SH2 & Boiler & SH1 & SH2 \\
\hline & & Outlet & Outlet & Outlet & Outlet & Outlet & Outlet \\
\hline \multirow{3}{*}{1.8} & \multirow{3}{*}{7} & 76.8 & 76 & 76.5 & 3 & 3 & 3 \\
\hline & & 76.6 & 95 & 96.7 & 3 & 3 & 3 \\
\hline & & 76.7 & 105 & 107 & 3 & 3 & 3 \\
\hline \multirow{3}{*}{1.8} & \multirow{3}{*}{5.5} & 77.5 & 76.5 & 77 & 5.6 & 5.6 & 5.6 \\
\hline & & 77.4 & 85 & 86.9 & 5.6 & 5.6 & 5.6 \\
\hline & & 77.4 & 101 & 103 & 5.6 & 5.6 & 5.6 \\
\hline
\end{tabular}

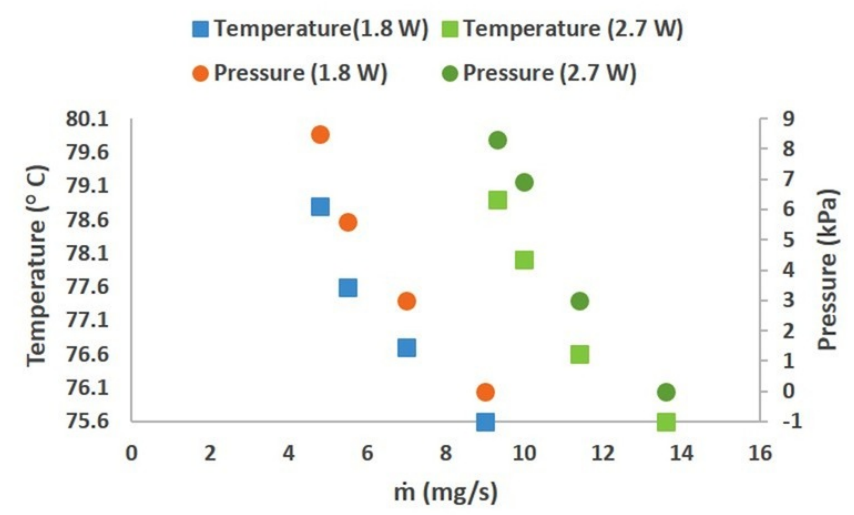

Figure 20: The plot of boiler operating pressure versus vapor temperature for all power inputs

\subsection{Superheater}

Following the Pressurized tests, specific superheating tests were performed. This was achieved via inclusion of super heater as shown in Figure 14 on the output flow from the steamdome. Power of $1.8 \mathrm{~W}$ was supplied to the boiler and the flow rate and operating pressure were based on Table 8. The flow rates of $7 \frac{\mathrm{mg}}{\mathrm{s}}$ and $5.5 \frac{\mathrm{mg}}{\mathrm{s}}$ with the operating pressure of $3 \mathrm{kPa}$ and $5.6 \mathrm{kPa}$ were selected. The temperature and pressure data were recorded at different 
locations of the setup (refer Table 1). Table 9 summarizes these recordings at the boiler and at the superheater.

The recorded data were then related to $3 M^{T M}$ provided HFE-7200 thermodynamic tables to interpolate entropy at specific temperature-pressure points. Figure 21 show the plot of temperature versus entropy. The plot establishes the boiler operation along the isobaric line of the working fluid.

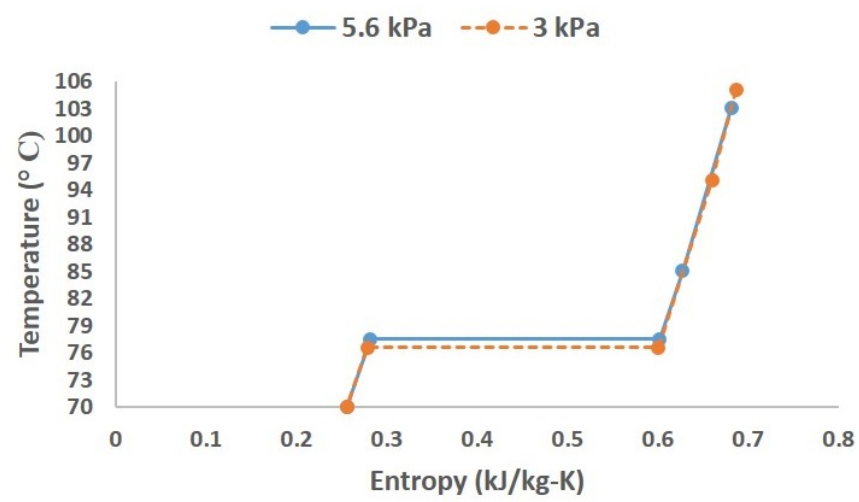

Figure 21: Temperature vs entropy plot of the boiler operation

With these insights into boiler characterization, further boiler development has been planned. The future work includes miniaturization of the superheater to incorporate it beneath the primary boiler plate. Such modification will allow the evaporated fluid exiting the steam dome to traverse the superheater utilizing a single heat source located beneath the boiler. This will better simulate a situation where a single heat source(like an Otto cycle) supplies heat to the entire system. 


\section{Conclusion}

The efficiency of a thermodynamically limited process could be improved by recovering the heat lost to the environment. One such approach is via installation of a waste heat recovery system. The system recovers the heat and converts it to useful work. Already established micro devices and engines provide such opportunity at low capital cost. In this work, a MEMS based boiler has been constructed and tested for such an application.

Several tests were performed to investigate the boiler operation. The Dry test provided the selection of power inputs and temperatures. The selected power inputs were $1.8 \mathrm{~W}$ and $2.7 \mathrm{~W}$ and the temperatures via conduction were $106^{\circ} \mathrm{C}$ and $144^{\circ} \mathrm{C}$, respectively. These temperatures were utilized to verify the finite difference method (FDM) model of the boiler. The validated model predicted the available power via conduction. The power was utilized to calculate fluid feed rate for the Wet tests. A working fluid was selected based on the realized operating temperatures of the dry boiler. In this work, 3MTM HFE-7200 was utilized. The evaluated mass flow rates were approximately $9 \mathrm{mg} / \mathrm{s}$ and $13.6 \mathrm{mg} / \mathrm{s}$ for the $1.8 \mathrm{~W}$ and $2.7 \mathrm{~W}$, respectively. These flow rates served as the baseline fluid feeds to the boiler in Wet tests.

In Wet tests, the ability of the capillary channels to pump fluid under atmospheric and pressurized environments was studied. In addition, a superheated test was performed by raising the steam temperature exiting the boiler. Based on available working fluid data for HFE-7200, a T-s chart was plotted that graphically established key isobaric operation and thermody- 
namic conditions of the boiler.

Operation of the boiler across these test points clearly showed the boiler as a potential future waste heat scavenging device. Radial capillary channels presented enhanced mass flow rate for phase transformation via capillary flow. In addition, a $500 \mathrm{~m}$ glass steamdome inclusion in the design reduced the boiler mass and the heat sink effect significantly versus prior boiler iterations. Such modification minimized the pre-condensation of vapor inside the steamdome. A maximum efficiency of approximately $88 \%$ was demonstrated by the boiler, an improvement of about $50 \%$ compared to previously published work [28]. Furthermore, the operating pressure of the boiler elevated as well. A peak operating pressure of $8.5 \mathrm{kPa}$ was demonstrated by the boiler.

With these significant improvements demonstrated by the present boiler design, future work will be focused on incorporating a superheater beneath the boiler. Such inclusion of a superheater will allow utilization of a single waste heat source (like an Otto cycle) for the entire system. Careful design and material selection of the superheater will be considered in order to maximize the heat transfer to the boiler via conduction.

\section{Acknowledgements}

The authors gratefully acknowledge the support of this work by the NSF via Grant No. ECCS-1053729. 


\section{References}

[1] M. Tahani, S. Javan, M. Biglari, A comprehensive study on waste heat recovery from internal combustion engines using organic Rankine cycle, Thermal Science 17 (2) (2013) 611-624.

[2] R. El Chammas, D. Clodic, Combined cycle for hybrid vehicles, Tech. Rep., SAE Technical Paper, 2005.

[3] I. Johnson, T. William, W. Choate, A. Amber Davidson, Waste heat recovery: technology and opportunities in US industry, US Department of Energy, Office of Energy Efficiency and Renewable Energy, Industrial Technologies Program .

[4] S. B. Viklund, M. T. Johansson, Technologies for utilization of industrial excess heat: Potentials for energy recovery and $\{\mathrm{CO} 2\}$ emission reduction, Energy Conversion and Management 77 (0) (2014) 369 - 379.

[5] E. Muntz, G. Shiftlett, D. Erwin, J. Kunc, Transient energy-release pressure-driven microdevices, Microelectromechanical Systems, Journal of 1 (3) (1992) 155-163.

[6] S. Spearing, K. Chen, Micro-Gas Turbine Engine Materials and Structures, in: Proceedings of the 21st Annual Conference on Composites, Advanced Ceramics, Materials, and Structures-B: Ceramic Engineering and Science Proceedings, Volume 18, Issue 4, Wiley Online Library, 11-18, 1997. 
[7] A. H. Epstein, S. A. Jacobson, J. M. Protz, L. G. Frechette, Shirtbuttonsized gas turbines: The engineering challenges of micro high speed rotating machinery, in: Proceedings, 8th Intl Symposium on Transport Phenomena and Dynamics of Rotating Machinery, Honolulu, HI, 1, 2000.

[8] C. Lee, L. G. Fréchette, A silicon microturbopump for a rankine-cycle power generation microsystemPart I: Component and system design, Microelectromechanical Systems, Journal of 20 (1) (2011) 312-325.

[9] C. Lee, K. Jiang, P. Jin, P. Prewett, Design and fabrication of a micro Wankel engine using MEMS technology, Microelectronic Engineering 73 (2004) 529-534.

[10] H. Aichlmayr, D. Kittelson, M. Zachariah, Miniature free-piston homogeneous charge compression ignition engine-compressor conceptPart I: performance estimation and design considerations unique to small dimensions, Chemical Engineering Science 57 (19) (2002) 4161-4171.

[11] S. Zhang, J. Wang, Z. Guo, Novel micro free-piston swing engine and its feasibility validation, Tsinghua Science and Technology 10 (3) (2005) 381-386.

[12] S. Whalen, M. Thompson, D. Bahr, C. Richards, R. Richards, Design, fabrication and testing of the P 3 micro heat engine, Sensors and Actuators A: Physical 104 (3) (2003) 290-298. 
[13] L. G. Fréchette, C. Lee, S. Arslan, Y.-C. Liu, Design of a microfabricated Rankine cycle steam turbine for power generation, in: ASME 2003 International Mechanical Engineering Congress and Exposition, American Society of Mechanical Engineers, 335-344, 2003.

[14] C. Lee, M. Liamini, L. G. Fréchette, A silicon microturbopump for a rankine-cycle power-generation microsystemPart II: Fabrication and characterization, Microelectromechanical Systems, Journal of 20 (1) (2011) 326-338.

[15] F. Vélez, J. J. Segovia, M. C. Martín, G. Antolín, F. Chejne, A. Quijano, A technical, economical and market review of organic Rankine cycles for the conversion of low-grade heat for power generation, Renewable and Sustainable Energy Reviews 16 (6) (2012) 4175-4189.

[16] P. J. Mago, R. Luck, Energetic and exergetic analysis of waste heat recovery from a microturbine using organic Rankine cycles, International Journal of Energy Research 37 (8) (2013) 888-898.

[17] T. Hung, Waste Heat Recovery of Organic Rankine Cycle using Dry Fluids, Energy Conversion and Management 42 (2001) 539-553.

[18] H. Chen, D. Y. Goswami, E. K. Stefanakos, A review of thermodynamic cycles and working fluids for the conversion of low-grade heat, Renewable and Sustainable Energy Reviews 14 (9) (2010) 3059-3067. 
[19] M. Antonelli, A. Baccioli, M. Francesconi, U. Desideri, L. Martorano, Operating maps of a rotary engine used as an expander for microgeneration with various working fluids, Applied Energy 113 (2014) 742750.

[20] S. A. Zulkifli, M. N. Karsiti, A. R. A. Aziz, Starting of a free-piston linear engine-generator by mechanical resonance and rectangular current commutation, in: Vehicle Power and Propulsion Conference, 2008. VPPC'08. IEEE, IEEE, 1-7, 2008.

[21] J. Jadhao, D. Thombare, Review on exhaust gas heat recovery for IC engine, International Journal of Engineering and Innovation Technology (IJEIT) Volume 2.

[22] B. Kongtragool, S. Wongwises, A review of solar-powered Stirling engines and low temperature differential Stirling engines, Renewable and Sustainable Energy Reviews 7 (2) (2003) 131-154.

[23] L. W. Weiss, C. D. Richards, R. F. Richards, Power output force generation by a mems phase change actuator, Microelectromechanical Systems, Journal of 20 (6) (2011) 1287-1297.

[24] E. Lurie, A. Kribus, Analysis of a microscale 'Saturation Phase-change Internal Carnot Engine', Energy Conversion and Management 51 (6) (2010) 1202 - 1209. 
[25] L. W. Weiss, Study of a mems-based free piston expander for energy sustainability, Journal of Mechanical Design 132 (9) (2010) 091002.

[26] C. Champagne, L. Weiss, Investigation of a MEMS-Based Boiler and Free Piston Expander for Energy Harvesting, in: ASME 2012 International Mechanical Engineering Congress and Exposition, American Society of Mechanical Engineers, 945-953, 2012.

[27] C. Champagne, L. Weiss, Performance analysis of a miniature free piston expander for waste heat energy harvesting, Energy Conversion and Management 76 (2013) 883-892.

[28] S. Thapa, E. Ogbonnaya, C. Champagne, L. Weiss, Mems-based boiler operation from low temperature heat transfer and thermal scavenging, Micromachines 3 (2) (2012) 331-344.

[29] B. Mathew, B. Jakub-Wood, E. Ogbonnaya, L. Weiss, Investigation of a MEMS-based capillary heat exchanger for thermal harvesting, International Journal of Heat and Mass Transfer 58 (1) (2013) 492-502.

[30] S. Thapa, J. Fang, D. Wood, L. Weiss, Investigation of Microboiler for Discarded Thermal Scavenging, in: ASME 2013 Heat Transfer Summer Conference collocated with the ASME 2013 7th International Conference on Energy Sustainability and the ASME 2013 11th International Conference on Fuel Cell Science, Engineering and Technology, American Society of Mechanical Engineers, V002T07A013-V002T07A013, 2013. 
[31] H. Lee, T. Quy, C. Richards, D. Bahr, R. Richards, Experimental and Numerical Study of Evaporative Heat Transfer From Ten-Micro Microchannels, in: ASME 2006 International Mechanical Engineering Congress and Exposition, American Society of Mechanical Engineers, $371-375,2006$.

[32] J. Wei, H. Xie, M. Nai, C. Wong, L. Lee, Low temperature wafer anodic bonding, Journal of Micromechanics and Microengineering 13 (2) (2003) 217.

[33] Y. Bäcklund, K. Hermansson, L. Smith, Bond-Strength Measurements Related to Silicon Surface Hydrophilicity, Journal of the Electrochemical Society 139 (8) (1992) 2299-2301.

[34] J. R. Armstead, S. A. Miers, Review of waste heat recovery mechanisms for internal combustion engines, Journal of Thermal Science and Engineering Applications 6 (1) (2014) 014001.

[35] M. S. Mohamed, J. L. Parker, Enhanced boiling of HFE-7100 dielectric liquid on porous graphite, Energy Conversion and Management 46 (2005) 2455-2481.

[36] M. El-Genk, J. Parker, Nucleate boiling of FC-72 and HFE-7100 on porous graphite at different orientations and liquid subcooling, Energy Conversion and Management 49 (2008) 733-750. 
${ }_{674}$ [37] S. J. Kline, F. McClintock, Describing uncertainties in single-sample 675 experiments, Mechanical engineering 75 (1) (1953) 3-8.

676 [38] 3M, Describing uncertainties in single-sample experiments, 3M 1 (1) $677 \quad(2003) 1-16$. 